\title{
Digital Financial Management
}

Data is the company's most important asset. We must manage data in the same way as we manage capital. Data is our strategic resource. As we comprehensively mine our data and use it more effectively, we are constantly uncovering and creating new opportunities and new value. High-quality data delivers multiple benefits: effective deployment of human resources, streamlined management, integrated business processes, higher operating efficiency, and more transparency in our business performance.

Data accuracy is the foundation for effective internal controls. To ensure the quality of our data, we need to ensure that all of our business data comes from a single source and is therefore traceable and that our business forecasts are reliable. Business process owners take full responsibility for the quality of the data generated from business transactions.

What should our financial management system look like in the era of big data? It should deliver data-driven business insights and ensure a balance between efficiency and control. The core goal of this system is to support sustainable and profitable growth. Finance needs to explore how to use data to provide business insights for all other departments across the company. Finance also needs to explore how to ensure effective control and risk management through optimized business models, resource allocation, and capital structure, as well as business and process transformations. The ultimate goal of Finance is to improve efficiency and drive sustainable and profitable growth of the company. 
The motto of our IT department is "Building roads is the first step to wealth." A large company needs to rely on automation, IT, and digital technologies to ensure smooth operations. In the field of accounting, it should actively pilot automation and the use of AI, handing over the accounting for standard scenarios to machines.

This chapter briefly describes how Huawei's Finance is going digital with clean data in the era of big data.

\subsection{Data Is a Strategic Resource}

\subsubsection{Managing Data in the Same Way as Managing Capital}

Data is one of the most critical elements in building the company's processes and management system. Smooth data flow is key to integrating our processes and supporting efficient operations of our management system. Data is our strategic asset, and data accuracy is the foundation for effective internal controls. Effective data management helps ensure data consistency, integrity, and accuracy throughout a process. It can also help improve operating efficiency, make well-informed decisions, ensure ICFR, and achieve other management goals. (Source: Resolution on Data Management, EMT Resolution No. [2016] 001)

We must take a holistic view at advances in our overall management system. We should build a well-coordinated management system and integrate processes from end to end in order to avoid silos caused by isolated transformations. We must also respect facts and prevent lies to ensure the consistency of business and accounts. Whenever possible, we should try to skip steps in the handover of internal operations data, as long as the necessary separation of duties is observed. This can help increase operating efficiency. (Ren Zhengfei: Applying the Spirit of the Tortoise to Catch up with the Dragon Spacecraft - Speech at Huawei Annual Management Conference 2013, Huawei Executive Office Speech No. [2013] 255)

Data is the company's most important asset, and data accuracy is the foundation for effective internal controls. Effective management of data value and risks can help streamline internal management, integrate business processes, improve operating efficiency, and create a clearer picture of actual business performance. (Source: Huawei Data Management Overview, Corp. Doc. No. [2014] 005)

In the era of big data, data has become a new type of economic asset, like hard currency or gold. We must manage data in the same way as we 
manage capital. We should use data to support our management, decisions, and innovation, which will drive sustainable and profitable growth of the company. Data is the most dazzling gem in our company's commercial crown. (Guo Ping: Financial Management in the Era of Big Data-Speech at the 2013 Annual Meeting of Finance, Improvement Issue No. 423, 2013)

Why do we place so much emphasis on data? The reason is quite simple. In today's business world, companies are like large ships afloat on an ocean of data. Only those that are able to sail on the blue ocean by leveraging big data capabilities can get rich returns. (Guo Ping: Financial Management in the Era of Big Data-Speech at the 2013 Annual Meeting of Finance, Improvement Issue No. 423, 2013)

Here are our takeaways regarding the implementation of the IPD process. Streamlined information in business flows is the basis for defining a process and an IT application architecture. This information is also the foundation for developing IT systems. Integrating major processes is essentially about smooth data flows. Data management is at the very heart of process and IT management. That's why we should take data seriously. (Xu Zhijun: Thoughts on the Relationships Between Business, Processes, IT, Quality, and Operations, Improvement Issue No. 421, 2013)

William Edwards Deming, the father of modern quality management, said: "In God we trust, all others must bring data." Data is the lifeblood of a company, and is the very soul of Finance. It is the smallest and the most accurate building block for logic within a business. (Guo Ping: Financial Management in the Era of Big Data-Speech at the 2013 Annual Meeting of Finance, Improvement Issue No. 423, 2013)

\subsubsection{Fully Leveraging Data Resources to Create New Competitive Advantages}

Data is our unique resource. Our IT systems, processes, and organization may be copied or imitated by others. Our employees may find a new job in another company. Only data truly belongs to us. If we can fully leverage our data resources to create innovative products and provide differentiated services to our customers, we can build core competencies that set us apart from our competitors. (Guo Ping: Financial Management in the Era of Big Data-Speech at the 2013 Annual Meeting of Finance, Improvement Issue No. 423, 2013) 
Data has become an increasingly valuable resource in the information society. As we comprehensively mine our data and use it more effectively, we are constantly uncovering and creating new opportunities and new value. During his two presidential campaigns, Barack Obama fully leveraged data analytics and data modeling. This enabled him to see the big picture and allocate resources to locations where he was most likely to win votes. (Meng Wanzhou: Discovering the Beauty of Data, 2013)

Finance must shift its focus from the past to the future. To make this shift, Finance must consider how to use data to better understand business trends and better support decision making. This will allow Finance to play a bigger role in driving the company's sustainable and profitable growth. (Guo Ping: Financial Management in the Era of Big Data-Speech at the 2013 Annual Meeting of Finance, Improvement Issue No. 423, 2013)

We can use data analytics to enhance our customer- and supplier-facing roles. This way, we can create new competitive advantages and improve our sources of profits. In particular, we can determine the most suitable contract terms and payment terms based on in-depth analyses of our customers and suppliers. We can also provide them with customized financial solutions through our analytics platform. We can collect and analyze postsales data in real time, and provide inputs for post-sales services, product quality control, and product design. We can also improve our demand forecasts and supply plans to increase inventory turnover. (Guo Ping: Financial Management in the Era of Big Data-Speech at the 2013 Annual Meeting of Finance, Improvement Issue No. 423, 2013)

We can use big data analytics to fully mine and analyze massive amounts of data regarding what our customers need. This will help us better understand our customers and work with them to create value. We need to analyze the massive amounts of data about contracts, orders, projects, configurations, inventory, and logistics within our company. This is vital to support timely, accurate, high-quality, and low-cost delivery. By applying big data analytics to human resources, we can optimize our approach to staffing and ensure that high-quality resources are allocated to valued customers. (Ren Zhengfei: Speech at the Awards Ceremony for Whiz Kids, Huawei Executive Office Speech No. [2014] 039) 


\subsection{Data Cleaning Is the Most Effective ApProach For InTERnal CONTrols}

\subsubsection{Ensuring Data Quality from the Source}

We must take data quality seriously and manage it from the source. There is still a lot of room for improvement when it comes to financial data accuracy and reliability. Data is not created by Finance; instead, all financial data comes from business. This is why I emphasize that data accuracy must be managed at the source in our business. If those who create data provide distorted data, Finance will be unable to effectively support operations and manage risks. (Meng Wanzhou: IFS: Working with Business Teams to Comprehensively Improve the Capabilities of Financial Staff, Improvement Issue No. 407, 2012)

Our business and financial teams must assume joint responsibility for data accuracy. The business team must hand over complete, accurate, and clear data to the financial team, and the financial team must process this data following the established regulations, rules, and processes. Managers should not interfere with process operations. They can only propose or initiate process optimization. The authenticity and accuracy of financial data depends on standardized front-end processes and clean data. The accounting department should face difficulties head on, assigning their best employees to field offices and integrating accounting requirements into their operations. Accounting personnel should get involved in the business to implement accounting requirements. The quality of financial data will only improve when front-end operations are standardized. (Ren Zhengfei: Speech at a Meeting with Staff in Mauritius, Huawei Executive Office Speech No. [2013] 016)

Business management at Huawei is data-based. Inaccurate basic data will result in inaccurate reporting data for business management activities. Inaccurate data doesn't truly reflect the nature of our business, nor can it serve as an effective guide for business management. (Xu Zhijun: Thoughts on the Relationships Between Business, Processes, IT, Quality, and Operations, Improvement Issue No. 421, 2013)

Key data must come from a single source. Data must be entered at a single point and made available at multiple points. Data quality must be assured from its source. (Source: Huawei Data Management Overview, Corp. Doc. No. [2014] 005)

Ideally, every procedure will create unique value, deliver exactly what the downstream procedure needs, and meet the quality requirements during this procedure. (Xu Zhijun: Thoughts on the Relationships Between Business, Processes, IT, Quality, and Operations, Improvement Issue No. 421, 2013) 
There are many factors that may affect the quality of data. Specifically, there are issues with data itself (like architecture, standards, integration, and IT compliance), business execution (unclear rules or improper execution), and $B C G$ compliance (business fraud or provision of false information). (Meng Wanzhou: Minutes of the Report on Data Work, 2015)

To get the process flowing, we first need smooth data flows. Why is a river crystal clear? Because fresh water flows from the spring. Data must be transmitted accurately and efficiently if we want to make it visible and easy-to-use throughout the process. That is what will make our management transparent. Currently, our data is not accurate and sometimes flows even more slowly than physical goods. This is mainly because we have not paid enough attention to data recording. The responsibility for keeping data flowing is not clearly defined. To address these problems, we first need to make sure data is recorded and recorded accurately, and that records are kept by experienced employees. Academic credentials should not be overemphasized. Data also needs to flow fast. Let's learn from high-speed rail networks. They have an ownership system every step of the way, ensuring things run on schedule and by the book. (Ren Zhengfei: Speech at the Oath-taking and Awards Ceremony of the Transformation Elite Team, Huawei Executive Office Speech No. [2015] 047)

In 2017, we aim to reach the level of "Basically satisfactory" for our overall data quality. That means we need to ensure that all of our business data comes from a single source and is therefore traceable and that our business forecasts are reliable. (Source: Resolution on Data Management, EMT Resolution No. [2016] 001)

High-quality data is the prerequisite and foundation for the use of AI. When we finish each procedure in our work, our first job is to look at whether high-quality data has been delivered. AI relies on data collected by thousands of employees, and then analyzes that data to find underlying patterns. Therefore, it is critical that we obtain clean and accurate data in the field. (Ren Zhengfei: Speech at the GTS Workshop on the Use of AI, Huawei Executive Office Speech No. [2017] 034)

\subsubsection{Whoever Creates Data Must Be Responsible for Data Quality}

Business managers must be responsible for process compliance, ensure that business data is accurate, timely, and standardized, and prevent their departments from committing fraud. They also need to have basic financial management capabilities and should take responsibility for oversight. 
Inaccurate and non-standardized business data will make it impossible to produce accurate financial reports. (Ren Zhengfei: Building a Highly Competitive Team-Speech at the Q3 Regional Presidents' Meeting, Huawei Executive Office Speech No. [2013] 093)

Whoever creates data must be responsible for the quality of the data. Data owners should develop data quality criteria that are in line with users' requirements and gain consent from any key departments that use the data. (Source: Huawei Data Management Overview, Corp. Doc. No. [2014] 005)

Data quality needs to be managed at two levels. The first level involves transformation teams and GPOs, who must manage data structures, standards, integration, and sources. The other level is the representative offices and SPDTs, who must be responsible for data quality at the source. GPOs must take overall responsibility for data quality, and establish and implement effective management mechanisms. The aim is to ensure all data items created within their domains are of high quality. Whoever generates or inputs data must be responsible for the quality of that data. Representative offices, SPDTs, and all their subordinate operating teams are the major sources of data, and therefore must be responsible for the quality of the data they generate. (Source: Resolution on Data Management, EMT Resolution No. [2016] 001)

Data is the company's most important asset, and data accuracy is the foundation for effective internal controls. Data owners need to manage data roadmaps, information architecture, data ownership systems, and data quality. They also need to release a termbase for data to unify all language related to data. All transformation projects must be managed in line with the data architecture. Data quality should be assessed by the departments that use the data. Those creating data should be held accountable for any data quality issues. We must clean our data sources and ensure that data is entered at a single point, and made available at multiple points. This can help ensure the quality of company data. (Source: Minutes of a Report by the Data Work Group, EMT Meeting Minutes No. [2014] 024)

Business process owners take full responsibility for the quality of business transaction data. They must ensure the accuracy, compliance, timeliness, integrity, and consistency of the raw data generated from business transactions. (Source: Financial Data Quality Management Policy, Finance Staff Team Doc. No. [2013] 048/Business Process \& IT Management Department Doc. No. [2013] 015) 
We must build a unified data foundation at the logic layer to provide accurate, reliable, and consistent data. By doing so, we can support Huawei's digital operations. We must also extensively mine data and extract its value in order to open up our data capabilities. We must manage data based on objects, and define the single source and owner for every piece of data. Data must be shared from the same source and provided as a service to ensure information consistency across platforms and systems. (Xu Zhijun: Improving and Complying with Our Enterprise Architecture to Support Agile Operations and Deliver a ROADS Experience-Speech at Huawei Enterprise Architecture and Process Management Conference 2016, Improvement Issue No. 518, 2017)

16.3 Making Routine Financial Management Automated and Intelligent, and Leveraging Big Data Analytics to Improve Financial Management

\subsubsection{The Basis of Scientific Management: Rational Analyses Based on Data and Facts}

We must underline the value of financial data. Financial reports are a window into how business units are doing, and must mirror their business performance in the current period. In financial reports, we should analyze gaps and develop and implement action plans according to the annual budget and rolling forecasts. While referring to historical data and checking against cost baselines, expense baselines, and targets on sales gross margins, we also need to analyze the data trends from multiple perspectives. We need to verify whether the management measures that we have taken are effective. Therefore, data rules must be able to guide management improvements. In addition, the rules must be stable and able to support comparisons with historical data. (Meng Wanzhou: Aligning Financial Settlements with Value Creation and Aligning Cross Charging for Incentive Purposes with Value Distribution, Huawei Executive Office Speech No. [2012] 040)

Rational analyses and decision making based on facts and data is actually a process of critical thinking. Critical thinking encourages us to be objective, humble, and fair. Critical thinking is also where creative thinking starts. Complexities in our business management can't be tackled by simply having a willingness to improve or by increasing headcount. This is why we still need to learn from the Whiz Kids. We must leverage the data- 
and fact-based scientific management approaches advocated by the Whiz Kids to analyze the root causes of problems and find methodical solutions. (Ren Zhengfei: Speech at the Awards Ceremony for Whiz Kids, Huawei Executive Office Speech No. [2014] 039)

Our delivery efficiency needs to be improved. You must begin to improve your own capabilities that are closely related to your work: correctly understanding customer needs; correctly drafting contracts; correctly entering contract information; correctly shipping items; correctly delivering items; and correctly providing services. Every step matters. In the first half of 2015, we had 6.4 million data entry errors. If your data was wrong during this period, then how could you possibly make a correct delivery? Do you have a crystal ball? Once our contract information is correct and the information is properly recorded, there is no excuse for shipment errors. Our stock managers must have enough experience. If they ship the wrong goods because they are unable to understand the orders, then that is enormously wasteful. Therefore, we must first of all correctly understand customer needs in order to get the contract right. But if we don't record the correct contract correctly, there is no way we can ship correctly. And if we don't ship correctly, it is impossible to make the correct delivery. (Ren Zhengfei: Generals Are Born of Battle-Speech at the 2015 Project Management Summit, Huawei Executive Office Speech No. [2015] 118)

Our Site Information Database should centrally manage information on sites and site operations (survey data, configuration, inventory, etc.). Data must be entered accurately to minimize the need to re-do any work. We need to achieve consistency of business and accounts. (Ren Zhengfei: Speech at the GTS Report on the Development of the Site Information, Geographic Information, and Dynamic Network Operations Databases and the Integrated Delivery Platform, Huawei Executive Office Speech No. [2015] 124)

We must have a standardized form, perhaps in an electronic format, for site information collection. Every person who visits a site should fill out this form, even if it's an emergency visit. It doesn't matter if it is filled out perfectly, and the next time someone goes to the same site, they can download the form filled out previously, and add any items they may have missed. In this way, the accuracy of data will improve. After repeating this process for three to five years, we will have a clear view of all our old accounts, and information regarding our new accounts will be fully available. (Ren Zhengfei: Speech at the GTS Report on the Development of the Site 
Information, Geographic Information, and Dynamic Network Operations Databases and the Integrated Delivery Platform, Huawei Executive Office Speech No. [2015] 124)

After the IT system is established, we need to make sure that data is carefully recorded every step of the way by people in every position, as this is necessary to reduce waste. There are several reasons for incorrect deliveries. First, the contract may be inaccurate because customer needs are not clearly understood. Second, if the contract is correct, its terms may be incorrectly entered into the system. Third, if the contract terms are correctly entered, the ordered products may be manufactured incorrectly. Finally, if the products are manufactured correctly, they may be shipped to the wrong recipient. Why does this happen? Because the people who ship the items cannot understand the contract. All of these problems result in huge waste for the company. If we can prevent these problems, we can achieve consistency of business and accounts and increase profits. Therefore, we require information to be strictly and accurately recorded. (Ren Zhengfei: Speech at the GTS Report on the Development of the Site Information, Geographic Information, and Dynamic Network Operations Databases and the Integrated Delivery Platform, Huawei Executive Office Speech No. [2015] 124)

\subsubsection{Establishing a Future-Proof Data Governance System}

Data management involves three main elements: ICFR data quality, data management system building, and business operations data. Data should be managed in two stages. In the first stage, we should focus on managing ICFR data quality and building a data management system. In the second stage, we should focus on managing business operations data. When setting data quality targets, we should rely on what is being managed, as well as the specific stage of implementation. (Meng Wanzhou: Minutes of the Report on Data Work, 2015)

We must always ensure our accounts reflect the true picture. But in the era of big data, we need more than that. We must also provide the smallest and the most accurate set of data, especially baseline data. This is the basic requirement you must meet as a business partner. All financial personnel should let the data speak for itself. Finance should establish business rules, and fully consolidate and analyze data. By doing so, Finance can support 
business management and help create business models geared toward the future. The era of big data presents both new challenges and opportunities for Finance. This is the biggest opportunity for Finance to leverage data to support company management. (Guo Ping: Financial Management in the Era of Big Data-Speech at the 2013 Annual Meeting of Finance, Improvement Issue No. 423, 2013)

We must ensure data is at the very heart of finance. To achieve this, Finance must build a future-oriented data governance system, develop a team of analysts with analytics expertise, and launch a big data strategy that relies on the smallest data set. (Guo Ping: Financial Management in the Era of Big Data-Speech at the 2013 Annual Meeting of Finance, Improvement Issue No. 423, 2013)

Data governance should be part of the operations management of the iSee system. We should enhance data governance through the use of data. Without data, there will be no iSee system. (Source: Resolution on the iSee System, Finance Staff Team Resolution No. [2013] 002)

Raw data can be processed and converted into information or statements by following pre-set rules. The key is to generate easy-to-understand and valuable information. Information or data can be used, analyzed, and then converted into intelligence that can support business management activities, inform decision making, and reveal risks. The key is to ensure that this intelligence can be effectively leveraged to deliver value. (Source: Resolution on the iSee System, Finance Staff Team Resolution No. [2013] 002)

We need to collect, consolidate, and classify data following basic financial rules and the paths of data generation, to prepare basic financial information. Then by combining financial personnel's understanding of data logic and business, we will identify opportunities and set objectives for management improvement during the process of data consolidation, gaining insights, modeling, and data analytics. This is the beauty of financial data. (Meng Wanzhou: Discovering the Beauty of Data, 2013)

CFOs have three key roles. They participate in and support strategic decision making, appraise performance and assess value, and act as a chief communication and coordination officer. To effectively fulfill these three roles, CFOs need solid, accurate, and reliable financial data. Financial analysis personnel and CFOs should go beyond data accuracy and delve deeper into the logic of data generation. They need to see both the trees and the forest. (Meng Wanzhou: Discovering the Beauty of Data, 2013) 


\subsubsection{Leveraging Automation, AI, and Big Data Analytics to Reduce the Complexity and Uncertainty of Financial Management}

In the era of big data, the core goal of our financial management system is to drive sustainable and profitable business growth

The core value of big data lies in its role in supporting forecasting. Forecasts help us understand business trends and track value transfer trends and their direction. This allows Finance to play a bigger role in future-oriented initiatives like driving sustainable and profitable growth, and optimizing resource allocation and the capital structure. (Guo Ping: Financial Management in the Era of Big Data-Speech at the 2013 Annual Meeting of Finance, Improvement Issue No. 423, 2013)

What should our financial management system look like in the era of big data? It should deliver data-driven business insights and ensure a balance between efficiency and control. The core goal of this system is to support sustainable and profitable growth. Finance needs to explore how to use data to provide business insights for all other departments across the company. Finance also needs to explore how to ensure effective control and risk management through optimized business models, resource allocation, and capital structure, as well as business and process transformations. The ultimate goal of Finance is to improve efficiency and drive sustainable and profitable growth of the company. (Guo Ping: Financial Management in the Era of Big Data-Speech at the 2013 Annual Meeting of Finance, Improvement Issue No. 423, 2013)

We need to use digital technologies to improve our internal operations and management, enable the fast flow of standard and digital information, and make the information flow transparent throughout the process. We should share information and enhance internal communication while fully mining and analyzing the massive amounts of company data. High-quality resources should be channeled to field offices, to support timely, accurate, high-quality, and low-cost delivery. We must create value together with our valued customers. (Guo Ping: Transform Continuously and Improve Field Operating Capabilities to Ensure the Company's Sustainable and Profitable Growth-Speech at Huawei Annual Management Conference 2013, Huawei Executive Office Speech No. [2014] 020)

In the past, one of the hardest jobs in the world was captaining a tanker. You had to know where the shoals lay, how ocean currents flowed, and the right moment to turn the rudder. There was danger everywhere. 
The Straits of Malacca are only 24 meters deep, but a 300,000 ton oil tanker might require 24.5 meters of water to prevent it from being grounded, so it must wait for high tide to get through. When the captain steps on the gas pedal, it takes more than 20 minutes for the tanker to actually start accelerating. How does the captain manage the tanker during this 20-plus minutes? I was recently in the Caribbean aboard a 170,000-ton American vessel, and I never saw the helmsman pilot the vessel, even docking was automated. Effectively and safely helming a vessel weighing hundreds of thousands of tons demands digital systems and automation. In the same way, managing a large company requires automation, IT, and digital technologies. (Ren Zhengfei: Speech at the GTS Report on the Development of the Site Information, Geographic Information, and Dynamic Network Operations Databases and the Integrated Delivery Platform, Huawei Executive Office Speech No. [2015] 124)

I often say to our IT department that if you want to get rich, build roads first. Our top priority is to solve the issue of broadband support in field offices and build experience centers more quickly. We should not hesitate to invest resources to solve this issue. It would even be worthwhile to rent satellites at high prices. We said we need to show more concern to our employees in hardship countries and regions. The first thing we should do is arrange for high-speed office networks and increase their bandwidth. Without a network, employees there may find it harder to finish their work, making them less efficient and progress more slowly. Broadband is a type of basic infrastructure, so expenses for broadband deployment and continued maintenance need to be borne by the company. Aren't all our offices in smaller countries equipped with telepresence systems? We can use the Experience Cloud to connect all our offices, enabling us to make experience and expert resources remotely accessible, worldwide. (Ren Zhengfei: Building Advanced Tools and Enhancing Core Competencies to Achieve Success at a Higher Level-Speech at a Carrier BG Briefing on the Service Experience and Phased Acceptance of the "Three Cloud" Platform, Huawei Executive Office Speech No. [2015] 099)

We encourage experts at all levels to analyze data to uncover patterns in their work. We can improve our work by automating or digitizing some processes. We also encourage AI research experts to become enablers for optimizing work throughout the company. We understand and support our scientists' theoretical research, but we also encourage them to use existing mature methodologies to improve our work. They can use these methodologies to automate or digitize some of our work processes, and 
help build the company's competitiveness for the future. Working smarter is one of our main goals. (Ren Zhengfei: Comments to "The Future of Artificial Intelligence Lies in Applications", Huawei Executive Office Speech No. [2017] 039)

When it comes to investing in AI, our strategy should be small applications first, to meet the most urgent needs. We should focus on businesses of certainty and projects that require large amounts of labor. At the beginning, less is more. We first need to apply AI in one or two scenarios, check whether it is really benefiting us, and then apply the technology to other scenarios. In the initial stage, we should not expect to apply AI too broadly or to go intelligent across many domains. Casting our net too wide will dilute the effect and result in failure. (Ren Zhengfei: Speech at the GTS Workshop on the Use of AI, Huawei Executive Office Speech No. [2017] 034)

In the field of accounting, we are actively piloting automation and use of AI, handing over the accounting in standard scenarios to machines. Currently, we handle an annual average of approximately 1.2 million expense claims from employees. Employees handle expense claim processes themselves, and machines directly generate accounting vouchers based on pre-set rules. There are 746 accounts in 98 countries that are now interconnected, with payment orders able to be transmitted to any given bank around the world within 2 minutes. Our payment accuracy is more than 100 times higher than that of banks. In four business scenarios in the accounts payable (AP) field, we have launched automated processing. Pilots have run for half a year, and parallel validations are being done manually. The results have thus far demonstrated an accuracy rate of 100\%. (Meng Wanzhou: Looking Back on the Path from Whence We Come, We See Only the Verdant Green Shimmering in the Majestic Setting Sun, 2017 New Year Greeting, 2016)

Our global program of radio frequency identification (RFID) asset management through the Internet of Things (IoT) is now implemented across 140,000 fixed assets at 2382 sites in 52 countries. RFID tags are attached to fixed assets that need to be managed. Every 5 minutes, the RFID tags automatically report a location signal, and once per day we update the usage load (or idle) data for the fixed assets. After deploying RFID, the time required to carry out fixed asset inventory work was reduced from a scale of months down to only a few minutes. For each year's asset inventory work and asset inspections, we saved upwards of 9000 person-days of workload. The timely update and sharing of asset location information and asset idle data really got us on track in our asset 
management. (Meng Wanzhou: Looking Back on the Path from Whence We Come, We See Only the Verdant Green Shimmering in the Majestic Setting Sun, 2017 New Year Greeting, 2016)

Building an integrated financial architecture ready for the next five to ten years

1. We are dealing with numerous services, changing models, an increasingly uncertain macro environment, and multiple business models. Therefore, Finance should be flexible and responsive to a wide range of requests.

2. Finance needs to leverage new technologies and architecture to enhance its capabilities and work more efficiently.

3. Finance should scientifically manage risks to meet the requirements of operations and compliance.

4. Finance should provide better support to business development with its responsiveness, smart decision making capabilities, foresight, and deductions.

5. Finance should expertly design a blueprint to help the company reach its goal of US\$200 billion in revenue, and design system integration based on that blueprint.

6. When designing an integrated financial architecture, Finance should give full consideration to the nature of our business, the logic of architecture, and the feasibility of technologies. We should use a distributed IT architecture to meet a range of needs; build 3 centers, 2 types of applications, and 2 platforms; and ensure our capabilities are real-time, automated, online (secure), agile, and able to achieve self-service and sharing. (Men Wanzhou: Minutes of the Workshop on the Integrated Financial Architecture to Support Huawei in Becoming a 200-billion-dollar Company, 2016) 
Open Access This chapter is licensed under the terms of the Creative Commons Attribution-NonCommercial-NoDerivatives 4.0 International License (http:// creativecommons.org/licenses/by-nc-nd/4.0/), which permits any noncommercial use, sharing, distribution and reproduction in any medium or format, as long as you give appropriate credit to the original author(s) and the source, provide a link to the Creative Commons licence and indicate if you modified the licensed material. You do not have permission under this license to share adapted material derived from this chapter or parts of it.

The images or other third party material in this chapter are included in the chapter's Creative Commons licence, unless indicated otherwise in a credit line to the material. If material is not included in the chapter's Creative Commons licence and your intended use is not permitted by statutory regulation or exceeds the permitted use, you will need to obtain permission directly from the copyright holder.

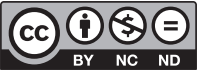

